\title{
The Hot Serial Cereal Experiment for modeling wheat response to temperature: field experiments and AgMIP-Wheat multi-model simulations
}

Pierre Martre ${ }^{1 *}$, Bruce A. Kimball ${ }^{2}$, Michael J. Ottman ${ }^{3}$, Gerard W. Wall ${ }^{2}$,Jeffrey W. White ${ }^{2}$, Senthold Asseng $^{4}$, Frank Ewert ${ }^{5}$, Davide Cammarano ${ }^{4}$, Andrea Maiorano ${ }^{1}$, Pramod K. Aggarwal ${ }^{6}$, Jakarat Anothai ${ }^{7}, B$ Buno Basso ${ }^{8}$, Christian Biernath ${ }^{9}$, Andrew J. Challinor ${ }^{10,11}$, Giacomo De Sanctis ${ }^{12, \$}$, Jordi Doltra $^{13}$, Benjamin Dumont ${ }^{8}$, Elias Fereres ${ }^{14,15}$, Margarita Garcia-Vila ${ }^{14,15}$, Sebastian Gayler ${ }^{16}$, Gerrit Hoogenboom ${ }^{7}$, Leslie A. Hunt ${ }^{17}$, Roberto C. Izaurralde ${ }^{18,19}$, Mohamed Jabloun ${ }^{20}$, Curtis D. Jones ${ }^{18}$, Belay. T. Kassie ${ }^{4}$, Kurt C. Kersebaum²1, Ann-Kristin Koehler ${ }^{10}$, Christoph Müller ${ }^{22}$, Soora Naresh Kumar $^{23}$, Bing Liu24, David B. Lobell ${ }^{25}$, Claas Nendel ${ }^{21}$, Garry O'Leary ${ }^{26}$, Jørgen E. Olesen ${ }^{20}$, Taru Palosuo $^{27}$, Eckart Priesack ${ }^{9}$, Ehsan Eyshi Rezaei ${ }^{5}$, Dominique Ripoche ${ }^{28}$, Reimund P. Rötter ${ }^{27}$, Mikhail A. Semenov ${ }^{29}$, Claudio Stöckle ${ }^{30}$, Pierre Stratonovitch ${ }^{29}$, Thilo Streck ${ }^{16}$, Iwan Supit ${ }^{31}$, Fulu Tao $^{27,32}$, Peter Thorburn ${ }^{33}$, Katharina Waha ${ }^{22}$, Enli Wang ${ }^{34}$, Joost Wolf ${ }^{31}$, Zhigan Zhao ${ }^{34,35}$ and Yan $\mathrm{Zhu}^{24}$

${ }^{1}$ LEPSE, Université Montpellier, INRA, Montpellier SupAgro, Montpellier, France.

2 USDA, Agricultural Research Service, U.S. Arid-Land Agricultural Research Center, Maricopa, AZ 85138, USA.

3 The School of Plant Sciences, University of Arizona, Tucson, AZ 85721, USA.

${ }^{4}$ Agricultural \& Biological Engineering Department, University of Florida, Gainesville, FL 32611, USA.

5 Institute of Crop Science and Resource Conservation (INRES), University of Bonn, 53115 Bonn, Germany.

${ }^{6}$ CGIAR Research Program on Climate Change, Agriculture and Food Security, BISA-CIMMYT, New Delhi-110012, India.

${ }^{7}$ AgWeatherNet Program, Washington State University, Prosser, WA 99350-8694, USA.

${ }^{8}$ Department of Geological Sciences and W.K. Kellogg Biological Station, Michigan State University East Lansing, MI 48823, USA.

9 Institute of Biochemical Plant Pathology, Helmholtz Zentrum München - German Research Center for Environmental Health, Neuherberg, 85764, Germany.

${ }^{10}$ Institute for Climate and Atmospheric Science, School of Earth and Environment, University of Leeds, Leeds LS29JT, UK.

${ }^{11}$ CGIAR-ESSP Program on Climate Change, Agriculture and Food Security, International Centre for Tropical Agriculture (CIAT), A.A. 6713, Cali, Colombia.

${ }^{12}$ European Food Safety Authority (EFSA), GMO Unit, Via Carlo Magno 1A, Parma, Italy.

${ }^{13}$ Cantabrian Agricultural Research and Training Centre (CIFA), 39600 Muriedas, Spain.

${ }^{14}$ Dep. Agronomia, University of Cordoba, Apartado 3048, 14080 Cordoba, Spain.

${ }^{15}$ IAS-CSIC, Cordoba 14080, Spain.

${ }^{16}$ Institute of Soil Science and Land Evaluation, University of Hohenheim, 70599 Stuttgart, Germany.

${ }^{17}$ Department of Plant Agriculture, University of Guelph, Guelph, ON N1G 2W1, Canada.

${ }^{18}$ Department of Geographical Sciences, Univ. of Maryland, College Park, MD 20742, USA.

19 Texas A\&M AgriLife Research and Extension Center, Texas A\&M University, Temple, TX 76502, USA.

20 Department of Agroecology, Aarhus University, 8830 Tjele, Denmark.

21 Institute of Landscape Systems Analysis, Leibniz Centre for Agricultural Landscape Research, 15374 Müncheberg, Germany.

22 Potsdam Institute for Climate Impact Research, 14473 Potsdam, Germany.

23 Centre for Environment Science and Climate Resilient Agriculture, Indian Agricultural Research Institute, IARI PUSA, New Delhi 110 012, India.

${ }^{24}$ National Engineering and Technology Center for Information Agriculture, Jiangsu Key Laboratory for Information Agriculture, Jiangsu Collaborative Innovation Center for Modern Crop Production, Nanjing Agricultural University, Nanjing, Jiangsu 210095, China.

25 Department of Environmental Earth System Science and Center on Food Security and the Environment, Stanford University, Stanford, CA 94305, USA.

26 Landscape \& Water Sciences, Department of Economic Development, Jobs, Transport and Resources, Horsham 3400, Australia.

${ }^{27}$ Natural Resources Institute Finland (Luke), 00790 Helsinki, Finland. 
28 INRA, US1116 AgroClim, 84914 Avignon, France.

${ }^{29}$ Computational and Systems Biology Department, Rothamsted Research, Harpenden, Herts, AL5 2JQ, UK.

${ }^{30}$ Biological Systems Engineering, Washington State University, Pullman, WA 99164-6120, USA.

31 PPS and WSG \& CALM, Wageningen University and Research, 6700AA Wageningen, The Netherlands.

32 Institute of Geographical Sciences and Natural Resources Research, Chinese Academy of Science, Beijing 100101, China.

${ }^{33}$ CSIRO Agriculture, St Lucia, Queensland 4067, Australia.

${ }^{34}$ CSIRO Agriculture, Black Mountain ACT 2601, Australia.

${ }^{35}$ College of Agronomy and Biotechnology, China Agricultural University, Beijing, 100193, China.

*e-mail: pierre.martre@inra.fr

Abstract: The dataset reported here includes the part of a Hot Serial Cereal Experiment (HSC) experiment recently used in the AgMIP-Wheat project to analyze the uncertainty of 30 wheat models and quantify their response to temperature. The HSC experiment was conducted in an open-field in a semiarid environment in the southwest USA. The data reported herein include one hard red spring wheat cultivar (Yecora Rojo) sown approximately every six weeks from December to August for a twoyear period for a total of 11 planting dates out of the 15 of the entire HSC experiment. The treatments were chosen to avoid any effects of frost on grain yields. For the late fall, winter, and early spring plantings, temperature free-air controlled enhancement (T-FACE) apparatus utilizing infrared heaters with supplemental irrigation were used to increase air temperature by $1.3^{\circ} \mathrm{C} / 2.7^{\circ} \mathrm{C}$ (day/night) with conditions equivalent to raising air temperature at constant relative humidity (i.e. as expected with global warming) during the whole crop growth cycle. Experimental data include local daily weather data, soil characteristics and initial conditions, detailed crop measurements taken at three growth stages during the growth cycle, and cultivar information. Simulations include both daily in-season and end-of-season results from 30 wheat models.

Keywords: wheat, field experimental data, heat stress, simulations.

1 ORIGINAL PURPOSE: The original purpose of this dataset was to support a model inter-comparison (Asseng et al., 2015) as part of the Agricultural Model Intercomparison and Improvement Project (AGMIP, http://www.agmip.org/; Rosenzweig et al., 2013). The field experimental data were from the Hot Serial Cereal (HSC) experiment carried out by the USDA Arid-Land Agricultural Research Center and the University of Arizona at Maricopa, Arizona to investigate the response of wheat development (White et al., 2011, 2012), gas exchange (Wall et al., 2011), growth, grain yield (Ottman et al., 2012;), canopy temperature and energy balance (Grant et al., 2011; Kimball et al., 2012) to supplemental heating and to seasonal air temperature from varied planting dates. This dataset is a unique source of information for meta-analyses of the impacts on temperature and heat on crop growth and yield and for benchmarking model improvement against a large ensemble of state-of-the-art wheat crop simulation models.

2 FIELD EXPERIMENTS: A full description of the experiment site and of the experiment treatment are found in Wall et al. (2001) and Ottman et al. (2012). The most important information for the plantings and heat treatments used in the AgMIP-Wheat project are summarized below for a comprehensive understanding of the dataset and to allow setting up simulations.

The experimental site was located at the University of Arizona's Maricopa Agricultural Center, Maricopa, Arizona, USA $\left(33^{\circ} 4^{\prime} \mathrm{N}, 111^{\circ} 58^{\prime} \mathrm{W}, 361 \mathrm{~m}\right.$ a.s.I.). Maricopa has a semiarid climate with mean annual solar radiation of $21 \mathrm{MJ} \mathrm{m}^{-2}$ day $^{-1}$, a mean annual temperature of $21^{\circ} \mathrm{C}$ and mean annual precipitation of $164 \mathrm{~mm}$. The soil was a Trix clay loam with low organic matter content described in Post et al. (1988). Wheat crops were sown approximately every six weeks from March 2007 through January 2009. The experimental design was a randomized complete block with three replicates. Seeds were sown at a rate of 288 seeds $\mathrm{m}^{-2}$ with a row spacing of $0.19 \mathrm{~m}$ to produce a final target plant density of approximately 200 plants $\mathrm{m}^{-2}$. Blocks were strips $11 \mathrm{~m}$ wide $\times 37 \mathrm{~m}$ long, allowing three $11 \mathrm{~m} \times 11 \mathrm{~m}$ plots per block. A circular (3-m diameter) (Control) plot was identified in the center of each block where plant measurements were taken. On four planting dates, two additional treatments were arranged in each block to yield a $3 \times 3$ Latin square experimental design, where heated plots were paired with Reference plots. The Heated plots were equipped with infrared heaters arranged to provide uniform warming over a 3-m diameter circular area as described in Kimball et al. (2008) (Figure 1). The 
Reference plots were equipped with dummy non-operable heaters to mimic the effect of the infrared heaters on the crop microclimate. In the data reported herein the Control and Reference treatments were pooled (see below).

Figure 1. Photograph of the infrared heater system. In the centre foreground, infrared heaters are arranged in a circle above a wheat crop (Heated plot), and in the background to the left, the dummy non-operable heaters are arranged in a similar configuration (Reference plots).

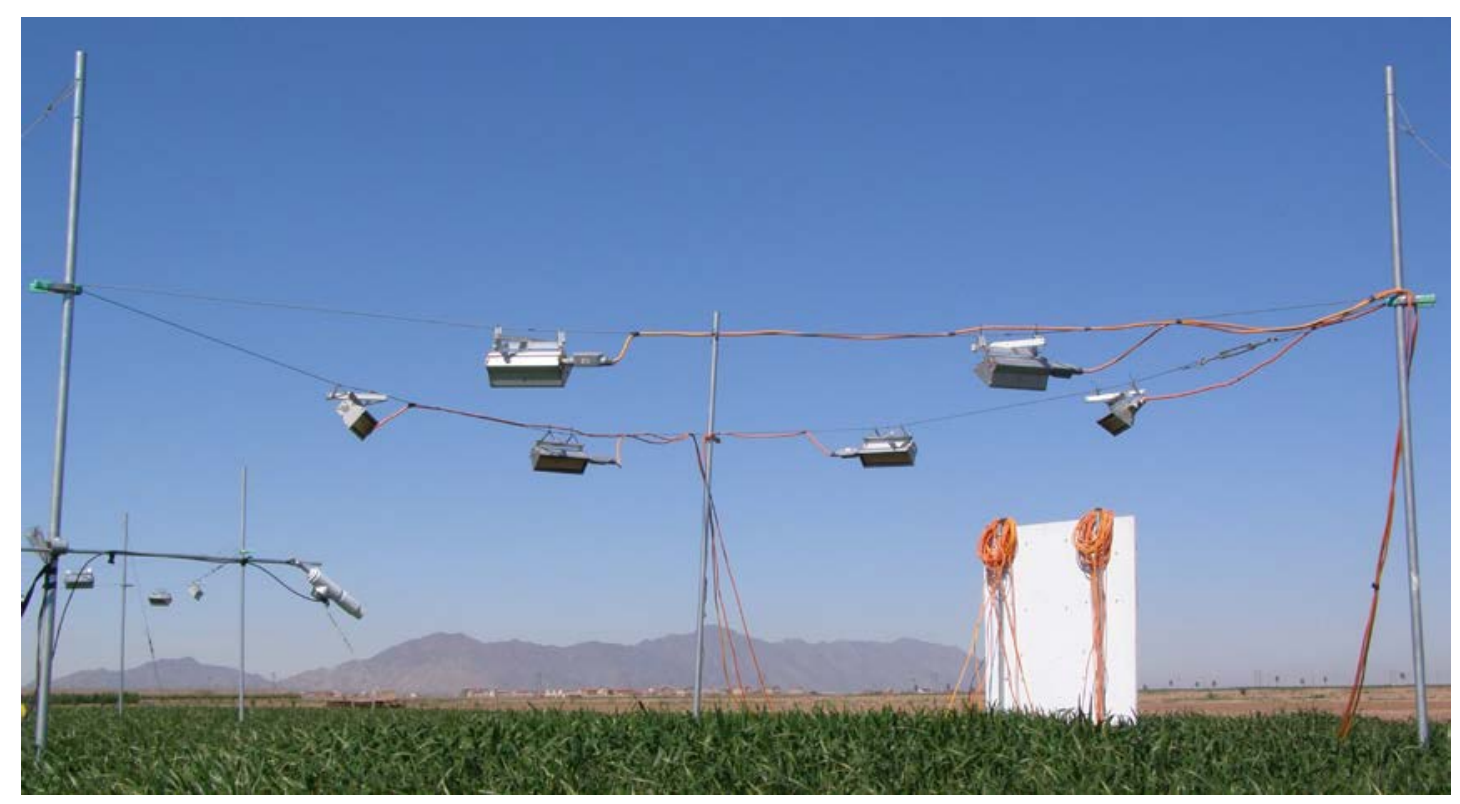

The crops were irrigated at $100 \%$ replacement of potential evapotranspiration to maintain the soil water content at field capacity. Depending on planting date, the total amount of irrigation ranged from 362 to $921 \mathrm{~mm}$. Water was supplied through a surface drip tape irrigation system with drip tapes placed $38 \mathrm{~cm}$ between every other row. Heated plots received $8 \%$ to $10 \%$ more water as a separate supplemental irrigation (except for the first planting on 13 March 2007) to provide a first-order correction for the increased plant-to-air vapor pressure gradient (Kimball, 2005). To guarantee good germination and emergence of the summer planted crops, additional sprinkler irrigation was provided. Soil fertility was managed to avoid nutrient limitations. Fifty to $56 \mathrm{~kg} \mathrm{~N} \mathrm{ha}^{-1}$ and $67 \mathrm{~kg} \mathrm{P}_{2} \mathrm{O}_{5} \mathrm{ha}^{-1}$ were applied as granular ammonium phosphate at planting, and urea ammonium nitrate was subsequently applied in irrigation water at rates of approximately $50 \mathrm{~kg} \mathrm{~N}^{-1}$ per application with up to four applications (at tillering, heading, anthesis and during grain filling) depending on crop requirements.

The date of drilling the seeds into dry soil is the "nominal" planting date, and the "effective" planting date is defined as the date irrigation water was first applied for seed germination and to fill the soil profile to field capacity, which occurred between one and eight days after the nominal planting date.

Each crop was sampled three times during the growing season for biomass and other crop growth parameters. The stages at sampling were before flag leaf emergence, after heading, and final harvest between physiological maturity and harvest ripe stage. Exceptions to the stages at sampling are the first sampling of the 13 March 2008 planting, which occurred between anthesis and the kernel milky stage, and the 13 February 2008 and 12 January 2009 plantings for which plants were also sampled after tillering. For the sampling times before maturity, dry mass, and nitrogen concentration of stems, green leaves, brown leaves, spikes, and crowns were determined. Leaf area index was calculated from the leaf laminae surface area and green area index was calculated from the sum of leaf, stem, and spike surface area. Grain and total plant yields were adjusted to a $0 \%$ moisture basis. Dates of crop emergence, anthesis and physiological maturity and final leaf number were determined as described in White et al. (2011). Figure 2 illustrates the exceptional range of grain yield and temperature in this dataset and the impact of the supplemental temperature treatments on grain yield.

The entire HSC experiment comprised 15 planting dates, but in both years the crop planted in September and October suffered from significant frost damage and were excluded from the model intercomparison study reported by Asseng et al. (2015), which focused on high temperature impacts. These four plantings are not reported here. Experimental data for these plantings and additional measurements for all plantings, including detailed phenological stages, leaf emergence rate (Haun 
stage), soil and canopy temperature, vegetation index (NDVI), leaf level gas exchange and water relations, and grain quality data are reported in a separate paper (Kimball et al., 2018).

Maximum and minimum values of daily air temperatures were obtained primarily from a weather station at the experimental field. When temperature data were unavailable, data were obtained from an Arizona Meteorological Network weather station (AZMET; http://ag.arizona.edu/azmet) located $1.2 \mathrm{~km}$ from the experiment site and were adjusted to match the on-site station values using a regression procedure. The wind and air temperature sensors were at 2-m height on the field mast, whereas wind was at $3 \mathrm{~m}$ and air temperature was at $1.5 \mathrm{~m}$ on the AZMET mast. Daily solar radiation, precipitation, mean wind speed and mean dew point temperature were obtained from the AZMET weather station. Seasonal (defined based on observed phenological stages) mean air temperature was calculated from daily air temperature, which was derived from the sum of eight contributions of a cosine variation between maximum and minimum daily air temperatures as described in Weir et al. (1984).

Figure 2. Final grain yield versus mean growing season temperature for the 11 plantings and the four Heat treatments of the HSC experiment reported here. The dashed lines connect the Control and supplemental Heat treatments of the same plantings. Control, average of the Control and Reference treatments; supplemental Heat, infrared warming (T-FACE) treatment. Data are mean \pm 1 s.d. for $n=3$ (for the supplemental Heat treatments and the Control treatments of plantings with no supplemental Heat treatment) to 6 (for the Control treatments of the plantings with supplemental Heat treatments) replicates.

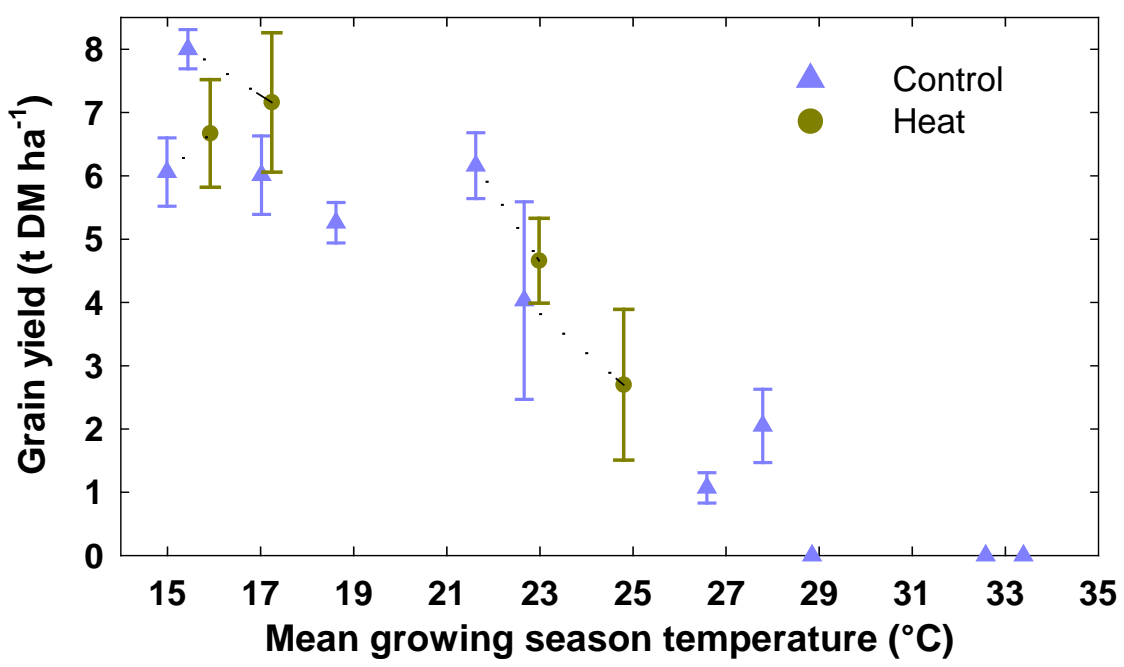

Results for the Reference and Control treatments were similar (Ottman et al. 2012), so they were pooled and named " $\mathrm{C}$ ". The Heat treatment was named " $\mathrm{H}$ ". Data are reported as mean and standard deviation. Missing data are indicated by "NA". Missing data correspond either to plant variables that were measured only at specific growth stages (e.g. grains were harvested only after anthesis) and to crops that died early in the growth season because of the summer heat (planting dates between June and August). In the latter case, final grain and chaff yield and nitrogen mass are equal to zero and the other variables are reported as NA.

3 SIMULATION OF FIELD EXPERIMENTS: The fifteen treatments described above were simulated by 30 wheat models (see Supplementary of Asseng et al., 2015). Simulations were carried out using standardized protocols and several steps of calibration. The simulation results reported here are for the full calibration step for which modelers had access to most of the experimental data reported here. For the simulations, the nominal planting dates were used. Some models were executed with water and nitrogen unlimited options. Fifteen of these 30 wheat models also participated in a model improvement exercise (Maiorano et al., 2017), where the HSC dataset was used for model improvement. For these fifteen models, simulation results are given for both the original and improved versions. 


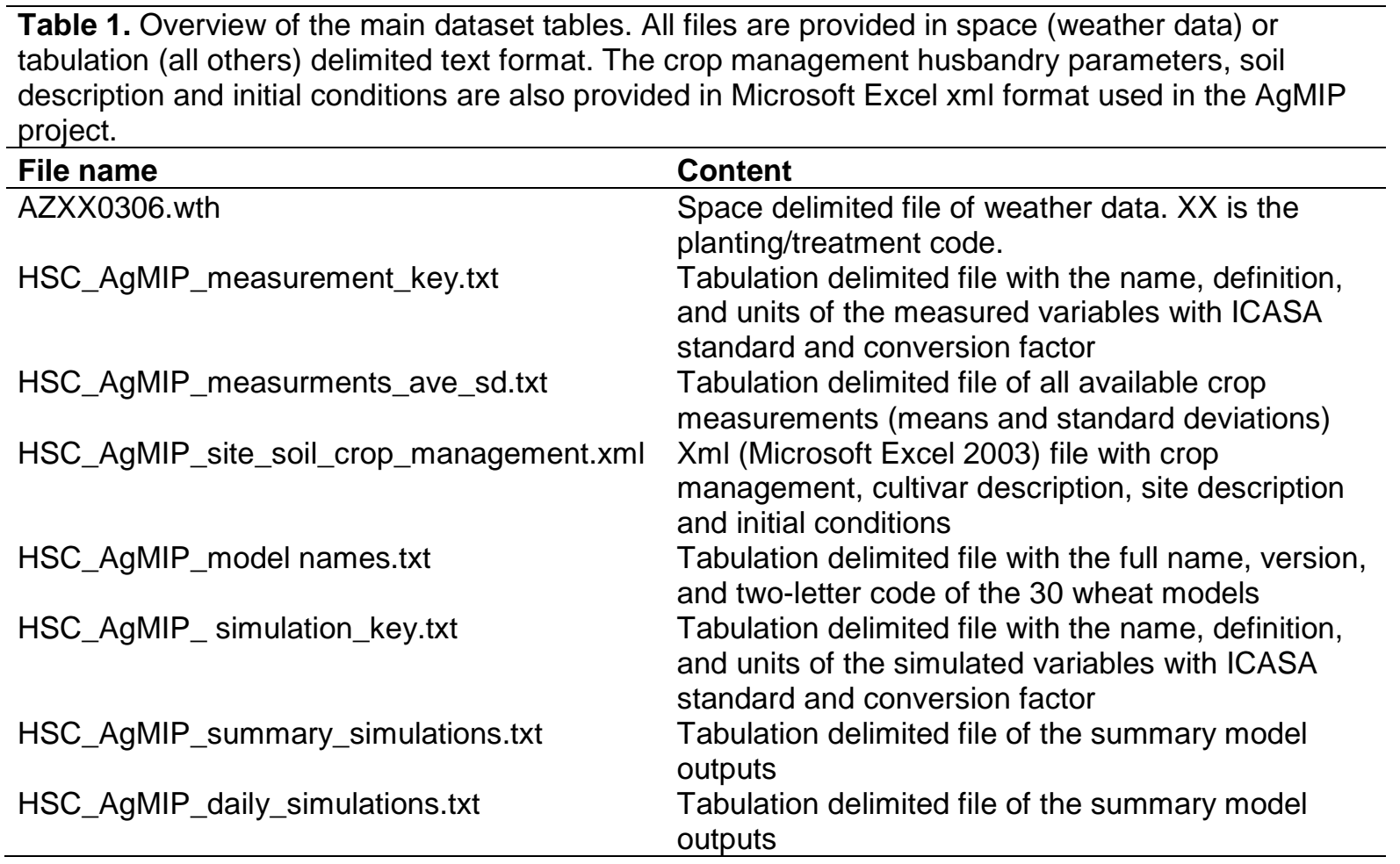

Model outputs include emerged leaf number (Haun stage), anthesis date, maturity date, grain dry mass and nitrogen yields, total above-ground biomass and nitrogen, leaf area index, number of grains per square meter, grain protein concentration, cumulative evapotranspiration, and cumulative transpiration. Not all models simulated all variables. Variables not simulated are indicated by "NA". Simulation results are reported for each individual model and for the multi-model ensemble median (e.median).

For the four plantings with Heat treatments, the three replicates of the Control and Heat treatments were simulated. The model inputs for the replicates differed only for the temperature and amount of irrigation. As no differences were observed between the replicates (as in the experimental data) in the data reported here, they were pooled. For the plantings without Heat treatments, only one replicate per planting was simulated. None of the Reference plots were simulated.

The experimental data presented here were also used in a modeling study of AgMIP-Wheat where canopy temperature models were evaluated for nine of the 30 wheat models used in Asseng et al. (2015) (Webber et al., 2016) and in an earlier study where energy balance and canopy temperature simulated by the wheat model ecosys were evaluated (Grant et al., 2011). Measured canopy temperature and energy balance data were reported in Kimball et al. (2018).

4 DATA FORMAT AND STRUCTURE: An overview of the main dataset tables is given in Table 1. Experimental (mean and standard deviation of crop measurements) and simulation (model output) data are provided in tab-delimited text files. The names of the variables (key) are explained in companion text files with their correspondence and conversion factors in the International Consortium for Agricultural Systems Applications standard - also known as the ICASA standard:

http://research.agmip.org/display/dev/ICASA+Master+Variable+List.

Model input (cultivar information and crop management), soil description and initial conditions for simulation set up are provided in a Microsoft Excel book in xml format following the AgMIP format for model input and in tabulation delimited text files. Daily weather data (global solar radiation, daily maximum and minimum temperature, rainfall, wind run, dew point temperature, vapor pressure, relative humidity) are provided in the ICASA format in space delimited text files.

5 ACKNOWLEDGEMENTS: We acknowledge the helpful cooperation of Dr. Robert Roth and his staff at the University of Arizona, Maricopa Agricultural Center, Maricopa, Arizona, USA. Technical assistance by Charles Blackshear, Matthew Conley, Steven Farnsworth, Justin Laughridge, Laura Olivieri, and Zahra Troeh is appreciated. 


\section{DISCLAIMER}

$\$$ The views or positions expressed in this publication do not necessarily represent in legal terms the official position of the European Food Safety Authority (EFSA). EFSA assumes no responsibility or liability for any errors or inaccuracies that may appear

\section{REFERENCES}

Asseng, S., F. Ewert, P. Martre, R. P. Rotter, D. B. Lobell, D. Cammarano, B. A. Kimball, M. J. Ottman, G. W. Wall, J. W. White, M. P. Reynolds, P. D. Alderman, P. V. V. Prasad, P. K. Aggarwal, J. Anothai, B. Basso, C. Biernath, A. J. Challinor, G. De Sanctis, J. Doltra, E. Fereres, M. GarciaVila, S. Gayler, G. Hoogenboom, L. A. Hunt, R. C. Izaurralde, M. Jabloun, C. D. Jones, K. C. Kersebaum, A. K. Koehler, C. Muller, S. Naresh Kumar, C. Nendel, G. O/'Leary, J. E. Olesen, T. Palosuo, E. Priesack, E. Eyshi Rezaei, A. C. Ruane, M. A. Semenov, I. Shcherbak, C. Stockle, P. Stratonovitch, T. Streck, I. Supit, F. Tao, P. J. Thorburn, K. Waha, E. Wang, D. Wallach, J. Wolf, Z. Zhao and Y. Zhu. 2015. "Rising Temperatures Reduce Global Wheat Production." Nature Climate Change 5(2):143-47. doi: 10.1038/nclimate2470.

Grant, R. F., B. A. Kimball, M. M. Conley, J. W. White, G. W. Wall and M. J. Ottman. 2011. "Controlled Warming Effects on Wheat Growth and Yield: Field Measurements and Modeling." Agronomy Journal 103(6):1742-54. doi: 10.2134/agronj2011.0158.

Kimball, B. A. 2005. "Theory and Performance of an Infrared Heater for Ecosystem Warming." Global Change Biology 11(11):2041-56. doi: 10.1111/j.1365-2486.2005.1028.x.

Kimball, B. A., M. M. Conley, S. Wang, X. Lin, C. Luo, J. Morgan and D. Smith. 2007. "Infrared Heater Arrays for Warming Ecosystem Field Plots." Global Change Biology 14(2):309-20. doi: 10.1111/j.1365-2486.2007.01486.x.

Kimball, B. A., J. W. White, G. W. Wall and M. J. Ottman. 2012. "Infrared-Warmed and Unwarmed Wheat Vegetation Indices Coalesce Using Canopy-Temperature-Based Growing Degree Days." Agronomy Journal 104(1):114-18. doi: 10.2134/agronj2011.0144.

Kimball, B. A., J. W. White, G. W. Wall, M. J. Ottman, P. Martre. 2018. "Wheat response to a wide range of temperatures, as determined from the Hot Serial Cereal (HSC) Experiment." Open Data Journal for Agricultural Research 4:16-21. doi: 10.18174/odjar.v4i0.15829.

Maiorano, A., P. Martre, S. Asseng, F. Ewert, C. Müller, R. P. Rötter, A. C. Ruane, M. A. Semenov, D. Wallach, E. Wang, P. D. Alderman, B. T. Kassie, C. Biernath, B. Basso, D. Cammarano, A. J. Challinor, J. Doltra, B. Dumont, E. Eyshi Rezaei, S. Gayler, K. C. Kersebaum, B. A. Kimball, A.-K. Koehler, B. Liu, G. J. O'Leary, J. E. Olesen, M. J. Ottman, E. Priesack, M. P. Reynolds, P. Stratonovitch, T. Streck, P. J. Thorburn, K. Waha, G. W. Wall, J. W. White, Z. Zhao and Y. Zhu. 2017. "Crop Model Improvements Reduce Multi-Model Ensembles High Temperature Impact Uncertainties." Field Crops Research 202:5-20. doi: 10.1016/j.fcr.2016.05.001.

Ottman, M. J., B. A. Kimball, J. W. White and G. W. Wall. 2012. "Wheat Growth Response to Increased Temperature from Varied Planting Dates and Supplemental Infrared Heating." Agronomy Journal 104(1):7-16. doi: 10.2134/agronj2011.0212.

Post, D. F., C. Mack, P. D. Camp and A.S. Suliman. 1988. "Mapping and Characterization of the Soils on the University of Arizona Maricopa Agricultural Center." Pp. 49-60 in 18th Proceedings of Hydrology and Water Resources of the Southwest, Arizona-Nevada Academy of Science.: Arizona-Nevada Academy of Science.hdl: 10150/296419.

Rosenzweig, C., J. W. Jones, J. L. Hatfield, A. C. Ruane, K. J. Boote, P. Thorburn, J. M. Antle, G. C. Nelson, C. Porter, S. Janssen, S. Asseng, B. Basso, F. Ewert, D. Wallach, G. Baigorria and J. M. Winter. 2013. "The Agricultural Model Intercomparison and Improvement Project (AgMIP): Protocols and Pilot Studies." Agricultural and Forest Meteorology 170(15):166-82. doi: 10.1016/j.agrformet.2012.09.011.

Webber, H., P. Martre, S. Asseng, B. Kimball, J. White, M. Ottman, G. W. Wall, G. De Sanctis, J. D., R. Grant, B. Kassie, A. Maiorano, J. E. Olesen, D. Ripoche, E. Eyshi Rezaei, M. A. Semenov, P. Stratonovitch and F. Ewert. 2016. "Canopy Temperature for Simulation of Heat Stress in Irrigated Wheat in a Semi-Arid Environment: A Multi-Model Comparison." Field Crops Research 202:21-35. doi: 10.1016/j.fcr.2015.10.009.

Wall, G. W., B. A. Kimball, J. W. White and M. J. Ottman. 2011. "Gas Exchange and Water Relations of Spring Wheat under Full-Season Infrared Warming." Global Change Biology 17(6):2113-33. doi: 10.1111/j.1365-2486.2011.02399.x.

Weir, A. H., P. L. Bragg, J. R. Porter and J. H. Rayner. 1984. "A Winter Wheat Crop Simulation Model without Water or Nutrient Limitations." Journal of Agricultural Science 102:371-82. doi: 10.1017/S0021859600042702. 
White, J. W., B. A. Kimball, G. W. Wall, M. J. Ottman and L. A. Hunt. 2011. "Responses of Time of Anthesis and Maturity to Sowing Dates and Infrared Warming in Spring Wheat." Field Crops Research 124(2):213-22. doi: 10.1016/i.fcr.2011.06.020.

White, J. W., B. A. Kimball, G. W. Wall and M. J. Ottman. 2012. "Cardinal Temperatures for Wheat Leaf Appearance as Assessed from Varied Sowing Dates and Infrared Warming." Field Crops Research 137(0):213-20. doi: 10.1016/.j.fcr.2012.08.013. 